This item was submitted to Loughborough's Research Repository by the author.

Items in Figshare are protected by copyright, with all rights reserved, unless otherwise indicated.

\title{
The effect of perceived psychological need support on amotivation in physical education
}

PLEASE CITE THE PUBLISHED VERSION

http://dx.doi.org/10.1177/1356336X15591341

\section{PUBLISHER}

Sage Publications / @ The Authors

VERSION

AM (Accepted Manuscript)

\section{PUBLISHER STATEMENT}

This work is made available according to the conditions of the Creative Commons Attribution-NonCommercialNoDerivatives 4.0 International (CC BY-NC-ND 4.0) licence. Full details of this licence are available at: https://creativecommons.org/licenses/by-nc-nd/4.0/

\section{LICENCE}

CC BY-NC-ND 4.0

\section{REPOSITORY RECORD}

Jackson-Kersey, Rachel, and Christopher M. Spray. 2019. "The Effect of Perceived Psychological Need Support on Amotivation in Physical Education”. figshare. https://hdl.handle.net/2134/18605. 


\section{EUROPEAW PHYSICAL EDUCATION REVIEW}

\section{The Effect of Perceived Psychological Need Support on Amotivation in Physical Education}

\begin{tabular}{|c|l|}
\hline Journal: & European Physical Education Review \\
\hline Manuscript ID: & EPE-14-0061.R2 \\
\hline Manuscript Type: & Original Manuscript \\
\hline Keywords: & $\begin{array}{l}\text { amotivation, perceived psychological need support, Physical Education, } \\
\text { Secondary }\end{array}$ \\
& $\begin{array}{l}\text { Physical educators have a responsibility to create a learning environment } \\
\text { that is viewed as supportive of students' psychological needs and which } \\
\text { helps reduce amotivation. The aim of the current study was to examine the } \\
\text { effects of students' perceived need support on four dimensions of } \\
\text { amotivation in Physical Education (PE) (deficiency in ability beliefs, } \\
\text { deficiency in effort beliefs, insufficient task values and unappealing task } \\
\text { characteristics). A longitudinal design was employed with three assessment } \\
\text { points over a six-week unit of work in cricket. Surveys were conducted with } \\
162 \text { boys (Mean age = 14 years, SD = 0.87) over three consecutive PE } \\
\text { lessons in weeks one, three and five. At the start of the study, multilevel } \\
\text { modelling analyses showed all three types of perceived need support } \\
\text { negatively predicted unappealing task characteristics and insufficient task } \\
\text { values. Over time, perceived autonomy, competence and relatedness } \\
\text { support negatively predicted change in unappealing task characteristics but } \\
\text { did not significantly predict change in deficiency in ability beliefs, deficiency } \\
\text { in effort beliefs and insufficient task values. Overall, the findings suggest } \\
\text { that if students perceive their teacher to provide inadequate support for } \\
\text { their basic psychological needs, PE tasks become less appealing over time, } \\
\text { thus reinforcing the importance of teachers in ameliorating the } \\
\text { development of specific amotivated behaviours in PE. }\end{array}$ \\
\hline Abstract \\
\hline
\end{tabular}


1 Running Head: THE EFFECT OF PERCEIVED NEED SUPPORT ON

2 AMOTIVATION

22 Submitted to: European PE Review 
European PE Review

\section{THE EFFECT OF PERCEIVED NEED SUPPORT ON AMOTIVATION}

\section{Abstract}

2 Physical educators have a responsibility to create a learning environment that is viewed

3 as supportive of students' psychological needs and which helps reduce amotivation. The

4 aim of the current study was to examine the effects of students' perceived need support

5 on four dimensions of amotivation in Physical Education (PE) (deficiency in ability

6 beliefs, deficiency in effort beliefs, insufficient task values and unappealing task

7 characteristics). A longitudinal design was employed with three assessment points over

8 a six-week unit of work in cricket. Surveys were conducted with 162 boys (Mean age =

914 years, $S D=0.87$ ) over three consecutive PE lessons in weeks one, three and five. At

10 the start of the study, multilevel modelling analyses showed all three types of perceived

11 need support negatively predicted unappealing task characteristics and insufficient task

12 values. Over time, perceived autonomy, competence and relatedness support negatively

13 predicted change in unappealing task characteristics but did not significantly predict

14 change in deficiency in ability beliefs, deficiency in effort beliefs and insufficient task

15 values. Overall, the findings suggest that if students perceive their teacher to provide

16 inadequate support for their basic psychological needs, PE tasks become less appealing

17 over time, thus reinforcing the importance of teachers in ameliorating the development

18 of specific amotivated behaviours in PE. 
1

2

3

4

5

6

7

8

9

10

11

12

13

14

15

16

17

18

19

20

21

22

23

24

25

26

27

28

29

30

31

32

33

34

35

36

37

38

39

40

41

42

43

44

45

46

47

48

49

50

51

52

53

54

55

56

57

58

59

60
THE EFFECT OF PERCEIVED NEED SUPPORT ON AMOTIVATION

1 Keywords: amotivation, perceived psychological need support, physical

2 education.

3

4

5

6

7

8

9

10

11

12

13

14

15

16

17

18

19

20

21

22

23

24

25 


\section{THE EFFECT OF PERCEIVED NEED SUPPORT ON AMOTIVATION}

1 The Effect of Perceived Psychological Need Support on Amotivation in Physical

\section{Education}

There is evidence in the literature to suggest that lack of physical activity in children can seriously affect their physical health, including risk of diabetes, high blood pressure, poor bone health and obesity (Gutin et al; 2004). For many children, school is the main environment for being physically active through physical education (PE) lessons and extra-curricular activities (Biddle et al; 1998). Therefore, schools offer an opportunity for teachers to deliver physical activities in a safe and structured way within a supportive environment (National Association for Sport and Physical Education; NASPE, 2005). The PE context provides the foundation for young people to learn how to be active and lead a healthy lifestyle (Biddle et al; 1998). However, health surveys in England have identified among boys a significant decrease over time in the proportion meeting physical activity guidelines. The decline has been increasingly marked in the older age group with $28 \%$ of boys meeting the government guidelines in 2008 compared with 14\% in 2012 (Health Survey for England (HSE), 2012). One reason for these results may be the decline in boys' motivation in PE over time. Sallis and Mackenzie (1991) argued that positive student motivation in PE could promote active healthy lifestyles in schools and beyond. On the contrary, if boys lack the motivation to engage in the lesson, maladaptive behaviours and negative student outcomes may follow such as disengagement, low participation and avoidance behaviours (Legault et al; 2006; Ntoumanis et al; 2004). Thus, physical educators are a powerful agent in developing students' self-determined motivation and to empower engagement in learning (Ryan and Deci, 2009).

According to self-determination theory (SDT; Deci and Ryan, 2000), teachers can influence a student's motivation by either supporting or thwarting the basic 
THE EFFECT OF PERCEIVED NEED SUPPORT ON AMOTIVATION

1 psychological needs of autonomy, competence and relatedness. In the PE context,

2 research has started to show that teaching behaviours that do not support the basic needs

3 and/or thwart these needs are related to amotivation and subsequent maladaptive student

4 outcomes (Ntoumanis et al; 2004; Shen et al; 2010b; Standage et al; 2005). According

5 to Deci and Ryan (2002), amotivation is a psychological state whereby an individual is

6 unable to identify an association between their behaviour and the outcome of their

7 behaviour, and amotivation is therefore an absence of motivation. Amotivated

8 individuals in PE tend to perceive the lesson to be of low importance, are unhappy with

9 the teaching style, and display behaviours such as forgetting PE kit and low attendance

10 (Ntoumanis et al; 2004). Given that educational research has shown a decline in

11 physical activity among adolescents (Malina and Katzmarzyk, 2006), it is important to

12 explore socio-contextual factors such as types of teachers' need support that may be

13 temporal antecedents of amotivation. For example, SDT literature has highlighted three

14 adaptive factors of the social environment (such as teachers' interpersonal style) that

15 may influence individuals' psychological needs (Reeve, Deci and Ryan, 2004). These

16 are autonomy support, structure and interpersonal involvement. Autonomy support

17 refers to behaviours from those in a position of authority (e.g. teachers) that allows

18 students provision of choice and freedom of expression. In addition, students' views are

19 acknowledged, and minimal pressure is ensued (Deci et al; 1994). Structure refers to

20 whether teachers provide clear instructions, set clear objectives and challenging goals,

21 and are consistent and predictable (Skinner and Edge, 2002). Finally, interpersonal

22 involvement refers to the willingness of teachers to provide empathy, affection, time

23 and energy to the students they interact with (Deci and Ryan, 1991; Reeve et al; 2004).

24 Work by Tessier and colleagues (2010) have identified the importance of the

25 aforementioned teacher behaviours by finding an increase in students' need satisfaction 


\section{THE EFFECT OF PERCEIVED NEED SUPPORT ON AMOTIVATION}

1 self-determination and engagement in PE.

\section{Amotivation}

Understanding the sources of students' lack of motivation is imperative to the

4 promotion of life long engagement and participation in physical activity. According to

5 self-determination theory, individuals may be motivated to participate in sport and

6 exercise activities for intrinsic and/or extrinsic reasons (Ryan and Deci, 2009). People

7 who are intrinsically motivated represent the highest form of self-determination and are

8 fully self-regulated having internalised the behaviour, engage in activities out of interest

9 and volition, and do not need external influences to encourage persistence (Deci and

10 Ryan, 1985, 2000). In contrast, extrinsic motivation refers to behaviours that are

11 determined by factors outside of the activity itself. SDT identifies four types of extrinsic

12 motivation, which are differentiated by the degree to which motives have become

13 internalised (Ryan and Deci, 2000). Internalisation stems from a mini-theory of SDT,

14 termed organismic integration theory (OIT; Deci and Ryan, 1985), and describes how

15 people accept or 'take in' the value of tasks to guide their behaviour. Amotivation

16 represents an absence of motivation and is evident when individuals lack the intention

17 and willingness to engage in a particular behaviour. Amotivation is a complete lack of

18 self-determination and may result if the individual lacks competence, devalues the

19 activity or is deficient in their abilities to achieve a desired outcome (Ryan and Deci,

20 2000). As amotivation lies on a continuum, the regulation of behaviour can become

21 more internalised if social environments and key social agents (such as the teacher)

22 support the internalisation process (Deci and Ryan, 2008).

23 Although the literature on motivation within PE is increasing, there remain

24 limited studies that have explored amotivation explicitly in the PE context. PE is a

25 compulsory subject, and therefore one is more likely to identify amotivated individuals 
THE EFFECT OF PERCEIVED NEED SUPPORT ON AMOTIVATION

1 in PE as opposed to extra-curricular activities. Amotivated behaviours may be

2 demonstrated in various ways, for example, failing to turn up to lessons with full PE kit,

3 opting to sit out of activities, playing sedentary roles, displaying a lack of effort, and

4 failing to learn new material (Ntoumanis et al; 2004; Sun and Cheng, 2008).

Recognising the importance of amotivation in the education context, Green-

6 Demers and colleagues, (2008) conceptualised and empirically validated amotivation as

7 a multi-dimensional construct consisting of four dimensions; deficiency in ability

8 beliefs, deficiency in effort beliefs, insufficient task values and unappealing task

9 characteristics. Studies in PE have supported the factorial validity of multidimensional

10 measures of amotivation (Shen et al; 2010a; Vlachopoulos et al; 2013).

11 Deficient ability beliefs describe students who believe they do not have the

12 ability to do well, and are therefore most vulnerable to being detached from school

13 (Eccles et al; 1993). Deficient effort beliefs are adopted when an individual fails to

14 expend the sustained effort asked of them to perform and maintain the behaviour. In a

15 PE setting, students may be reluctant to get involved in game situations or activities,

16 and opt to play more stationary roles that require less physical effort. Furthermore,

17 Ryan and Deci (2000) included lack of value as part of the definition of amotivation and

18 subsequently insufficient task values comprises one of the four amotivation dimensions.

19 Therefore, if an individual devalues PE they may uphold negative attitudes towards the

20 subject and consequently experience motivational deficits (Wigfield and Eccles, 2000).

21 Finally, unappealing task characteristics are related to feelings of boredom, which have

22 been linked to amotivation in past research (Ainley et al; 2002; Legault et al; 2006;

23 Ntoumanis, 2001; Ntoumanis et al; 2004). Tasks that are deemed as too challenging for

24 students can also induce boredom (Standage et al; 2005). Students are more likely to be

25 enthusiastic if they deem an activity interesting (Hidi and Harackiewicz, 2000), and 


\section{THE EFFECT OF PERCEIVED NEED SUPPORT ON AMOTIVATION}

1 therefore it is imperative that teachers create a stimulating environment for their

2 students to capture their interest.

\section{Need support}

4

5

6

The social environment strongly influences motivation behaviours by supplying "fundamental nutriments" referred to as basic psychological needs; autonomy (a sense of volitional control), competence (effectively interacting with the environment to yield desired outcomes) and relatedness (feeling connected with significant others) (Deci and Ryan, 2000). Basic psychological needs theory (BPNT), another subtheory of SDT, suggests that when these basic needs are supported in our social environment, individuals' need satisfaction increases which then promotes a sense of selfdetermination. Thus, teachers have a pivotal role in enhancing more autonomous forms of motivation in PE.

Autonomy support from teachers should intend to foster 'volitional intentions to act' so students feel they are in control over their choices and actions (Reeve and Jang, 2006) Teachers may provide students with a range of different ways to solve a problem or complete a task so the student feels they are self directing their behaviour, and as a result increase their levels of self-determined motivation (Ward et al; 2008). In PE for example, teachers would be showing autonomy support by finding ways to increase students' values towards specific activities, tactics and concepts, via for example providing meaningful rationale for activities and particular tasks. In so doing, students will gain a sense of meaning and control over their actions (Reeve and Jang, 2006).

Research needs to explore whether low perceived autonomy support may be closely associated with insufficient task values and consequently help foster amotivated behaviours. Competence support from teachers may involve positive feedback and encouragement during and after the lesson, setting differentiated tasks, allowing 
THE EFFECT OF PERCEIVED NEED SUPPORT ON AMOTIVATION

1 sufficient practice time, and helping students to focus on the process of learning a skill

2 rather than the outcome (Alderman et al; 2006). Low competence may be linked to

3 deficiency in ability beliefs and, therefore, one would expect students to experience

4 higher levels of amotivation if the teacher does not support this need. Lastly relatedness

5 support from teachers and classmates has been highlighted in the literature as being an

6 important need that is crucial among students at school (Koka and Hagger, 2010;

7 Perlman, 2010; Vallerand, 2001). Providing opportunities for students to feel connected

8 with their peers and teachers is essential, and the PE context is an environment whereby

9 students have the opportunity to develop positive relationships with others. If teachers

10 demonstrate willingness to care for their students, provide empathy and support for their

11 feelings towards different activities, and interact with students, then this will help

12 students' motivational development (Shen et al; 2010b; Standage et al; 2006).

13 Empirical work in students' perception of psychological need support and

14 amotivation has been demonstrated by Shen and colleagues (2010b). Shen and co-

15 workers conducted a study investigating the influence of inadequate teacher-to-student

16 social support on amotivation among high-school physical education students in the

17 United States. They particularly looked at the different dimensions of amotivation to see

18 whether the perceptions of need support from the teacher influenced the amotivation

19 subtypes. They found that teacher relatedness support was negatively associated with

20 insufficient task values and unappealing task characteristics; teachers' autonomy

21 support was not associated with any of the four amotivation dimensions, and

22 competence support strongly predicted all four types of amotivation. However, one

23 limitation of their study was the cross-sectional design, which consequently confines the

24 researchers to only explore correlates of amotivation at one time point. To date, most

25 studies in PE have examined amotivation as a uni-dimensional construct using cross- 
THE EFFECT OF PERCEIVED NEED SUPPORT ON AMOTIVATION

1 sectional designs. A more comprehensive understanding of amotivation in PE using a

2 longitudinal perspective is needed to attempt to understand the ways in which students'

3 perceptions of teacher need support may affect students' amotivation whilst students

4 gain more experience working with their teacher. One may assume that with effective

5 teaching, students' perception of psychological need support will increase, together with

6 students' self-determined motivation. However, this may not be the case, and some

7 students may perceive their teacher to be unsupportive of their needs and subsequently

8 could have a maladaptive effect on students' behaviour.

9 The current study, therefore, aimed to shed light on whether low perceptions of

10 psychological need support predicts the development of amotivation over time. Yet

11 recent amotivation research has shown the importance of controlling for confounding

12 influences. Jackson-Kersey and Spray (2013) for example, highlighted the negative

13 relationship between deficient ability beliefs and physical self-concept (PSC). PSC

14 being defined as an individuals' perception of his or her appearance, body fat, co-

15 ordination and other aspects of the physical self (Marsh et al; 1994) The present

16 investigation therefore controlled for PSC in determining the effects of teacher need

17 support on the amotivation subtypes across a six-week unit of work in PE. A unit of

18 work is a planned sequence of lessons over a short time period (5-6 weeks) that is

19 focused on one activity, and details progression and learning outcomes throughout the

20 unit. Due to limited research on the amotivation dimensions and inadequate teacher

21 psychological need support, caution was observed in proposing specific hypotheses.

22 However, in line with theoretical predictions it was anticipated that perceived

23 autonomy, competence and relatedness support would be negatively associated with the

24 four amotivation dimensions over time. 


\section{THE EFFECT OF PERCEIVED NEED SUPPORT ON AMOTIVATION}

Method

\section{Participants}

3

4 England of which 162 boys (mean age $=14$ years, $\mathrm{SD}=0.87$ ) from Year 9 took part in

5 the study. The majority of students were of middle socio-economic status. Year 9 was

6 chosen for our sample as physical activity in boys during adolescence is declining and

7 the older age group has been marked as the most problematic (HSE, 2012). Participants

8 took part in a minimum of one hour of physical activity per week in the form of a games

9 lesson, and one hour of PE per week on a fortnightly rotation. It was decided that data

10 collection took place in a PE lesson as opposed to a games lesson as PE provides a more

11 structured environment whereby students remain in the same class every lesson and are

12 taught by the same teacher. In addition, all teachers were required to teach a unit of

13 work in the chosen activity (cricket) to ensure all students in all classes were taught the

14 required skills and tactics. Six PE classes of approximately 30 boys in each class took

15 part in the study. All participants were taught a programme of work on cricket which

16 consisted of six lessons over 6 weeks. Two male teachers taught these classes at

17 different times during the week, and individual classes were consistently taught by the

18 same teacher throughout the unit of work. All students had been taught by their class

19 teacher for eight months prior to data collection, and some students would have been

20 taught by the class teacher in previous school years and in extra-curricular activities.

\section{Measures}

Amotivation in Physical Education: To assess students' amotivation in cricket,

23 the Amotivation Inventory in Physical Education (AI-PE) (Shen, 2010a) was adapted.

24 The AI-PE consists of 16 items measuring the four dimensions of amotivation: 
THE EFFECT OF PERCEIVED NEED SUPPORT ON AMOTIVATION

1 effort beliefs (e.g. 'I'm not energetic enough'); Unappealing characteristics of the task

2 (e.g. 'My cricket lessons are not stimulating'); and Insufficient task values (e.g. 'Cricket

3 is not valuable to me'). Students were firstly instructed to state on a Likert-scale $(1=$

4 Never to $7=$ Always) 'how often do you feel a lack of motivation to do cricket'. They

5 were then asked to rate on a Likert-scale from 1-7 $(1=$ does not correspond at all to $7=$

6 corresponds exactly) each statement that corresponded with their reasons for not

7 wanting to do PE. Mean scores were then calculated at each time point. Evidence for the

8 reliability and validity of the AI-PE has been supported by Shen et al. (2010a).

9 Student perceptions of teacher need support: Students' perceptions of

10 autonomy support were measured using a PE modified version of the Learning Climate

11 Questionnaire (LCQ) adapted by Standage et al, (2005). In the present study, four items

12 were extracted from the 15-item LCQ to measure autonomy need support. To measure

13 competence need support and relatedness need support, four items for each variable

14 were adapted from the questionnaire devised by Standage and colleagues (2005).

15 Students were asked to rate on a Likert scale $(1=$ Not at all true: $7=$ Very true $)$ how

16 true each statement was in relation to the PE class they had just participated in and the

17 PE teacher who taught them. Each item was preceded by the stem, "In this PE class..."

18 There were 12 items overall measuring support for three needs; autonomy support (e.g.

19 'I feel the PE teacher provided us with choices and options'); competence support (e.g.

20 'I feel the PE teacher helped me to improve') and relatedness support (e.g. 'The PE

21 teacher supported us'). Mean scores were then calculated at each time point. Evidence

22 for the reliability and validity of the LCQ and the competence and relatedness support

23 items were supported by Standage et al. (2005).

\section{Procedures}




\section{THE EFFECT OF PERCEIVED NEED SUPPORT ON AMOTIVATION}

2 was first obtained from the head teacher, followed by parental consent. Letters were

3 sent to parents explaining the aims of the study and their right to reply if consent was

4 not granted. No parent chose this option. All participants completed an informed assent

5 form at the start of the study, detailing the class that they were in and their date of birth.

6 Participants were informed that they had the right to withdraw at any time and all

7 responses would remain anonymous. They were told that there were no right or wrong

8 answers and to answer honestly. All participants were given a multi-section

9 questionnaire at the end of their PE lessons, which took approximately fifteen minutes

10 to complete. Questionnaires were administered in week 1, 3 and 5 during the 6-week

11 unit of cricket in the summer term to measure students' responses at the beginning,

12 middle and end of the unit. Students were asked for their date of birth at the start of

13 completing every questionnaire so responses could be matched over the three time

14 points.

\section{Data analytic strategy}

16 Descriptive statistics and internal reliability coefficients (Cronbach's alpha)

17 were first calculated for all study variables across all measurement waves. Given we

18 adapted the AI-PE in the present study to relate to cricket, it felt prudent to check the

19 factor structure. This was done through confirmatory factor analysis (CFA). To explore

20 the relationships between the amotivation scores and the other variables, correlations

21 were assessed at each time point among the amotivation dimensions, perceptions of

22 teacher need support, and PSC. Next, unconditional means models were examined to

23 ascertain the intraclass correlations of all study variables i.e. to determine the proportion

24 of variance explained at different levels. Subsequently, unconditional growth models

25 were tested to identify average patterns of change across the study for each variable. 
THE EFFECT OF PERCEIVED NEED SUPPORT ON AMOTIVATION

2 dimensions could be predicted by change in perceptions of teachers' need support

3 whilst controlling for PSC. Multilevel regression analyses employing MLwiN 2.23

4 (Rashbash et al; 2009) were used to examine change in student amotivation. This type

5 of analysis is useful when there are missing observations since it does not assume an

6 equal number of measurement occasions for all individuals (Hox, 2002). Level 1

7 analysis encompassed the repeated observations of amotivation sub-types, PSC, and

8 students' perceptions of teacher need support nested within students (level 2). Time was

9 centered at wave one, intercepts were allowed to vary randomly across levels and all

10 predictor variables were grand-mean centered. For each dependent variable, the model

11 tested the fixed effects of perceptions of teacher need support and PSC at the start of the

12 study (initial status) and over time. Additional analyses explored whether results

13 differed when not controlling for PSC. Due to finding no substantial change in the

14 results for each analysis, PSC was subsequently removed from the final multilevel

15 models.

\section{Results}

\section{Preliminary analyses}

18 Factor analysis. Confirmatory factor analysis (CFA) was employed using EQS

19 (version 6.1; Bentler, 2003) to determine the factor structure of the scale used to

20 measure amotivation. Recent research has found the AI-PE to consist of four correlated

21 factors (Jackson-Kersey and Spray, 2013), representing the four amotivation

22 dimensions. Examination of the fit indices indicated that the data adequately fit the four-

23 factor model $(\mathrm{CFI}=.95, \mathrm{NNFI}=.94, \mathrm{SRMSR}=.05, \mathrm{RMSEA}=.06)$. Bentler $(2003)$

24 proposed that good fit of a hypothesised model to the data is indicated when the CFI is

$25 \geq .95$, the SRMR is $\leq .08$, and the RMSEA is $\leq .06$. 
2 variables were calculated for each of the three time points (see Table 1). The mean

3 scores for amotivation were below the midpoint suggesting a low amotivated sample

4 and the mean scores for perceived support for autonomy, competence and relatedness

5 were all above the midpoint, suggesting the sample on average felt their needs were

6 being supported by the teacher. All scales were above alpha $=0.82$ indicating good

7 internal consistency. Correlations were assessed among all variables at each time point

8 and correlations from the first assessment point are shown in Table 2. These analyses

9 revealed that teacher autonomy, competence and relatedness support was significantly

10 inversely correlated with deficiency in ability beliefs, insufficient task values and

11 unappealing task characteristics but no significant correlations were found with

12 deficient effort beliefs.

13 Unconditional means models. Unconditional means models were calculated for

14 each variable to determine the intraclass correlation (ICC) for each variable at the

15 student level. An unconditional means model has no predictors at either level and

16 identifies whether there is systematic variation in the variable worth exploring, as well

17 as whether the variation lies within- or between-individuals (Singer and Willett, 2003).

18 There was sufficient between-person variation in the intercepts (ICCs ranged from .48

19 to .65). Within-person variation in the intercepts ranged from .35 to .52 across the three 20 time points.

21 Unconditional growth models. Unconditional growth models, with time serving

22 as the only predictor, showed, on average, non-significant changes in all four

23 amotivation dimensions over the three time points. However, students' perceptions of

24 autonomy support $(\beta=0.17)$ showed a significant increase over time, whereas 
European PE Review

THE EFFECT OF PERCEIVED NEED SUPPORT ON AMOTIVATION

1 competence $(\beta=-0.30)$ and relatedness support $(\beta=-0.28)$ demonstrated a significant

2 decrease.

3 Main analyses

$4 \quad$ Predicting change in amotivation across the unit of work. Conditional growth

5 models (see Table 3) were constructed exploring potential changes in the intercept and

6 slope (i.e. rate of change) of the amotivation dimensions and perceptions of need

7 support. A series of models were estimated with students' perceptions of autonomy,

8 competence and relatedness support predicting within-and between-person change in

9 the four amotivation dimensions. At the start of the study, teacher support for all three

10 needs negatively predicted insufficient task values (autonomy NS $(\beta=.15, S E=.06$ ),

11 competence $N S(\beta=.17, S E=.06)$, relatedness $N S(\beta=.15, S E=.06)$ and unappealing

12 task characteristics (autonomy $N S(\beta=.17, S E=.06)$, competence $N S(\beta=.19, S E=$

$13.06)$, relatedness $N S(\beta=.16, S E=.06)$. Competence support negatively predicted

14 deficiency in ability beliefs $(\beta=.10, S E=.05)$. Deficiency in effort beliefs was not

15 predicted by any of the three types of support $(p>.05)$. Over time, however changes in

16 perceived teacher support for all three needs negatively predicted changes in

17 unappealing task characteristics (autonomy NS $(\beta=.08, S E=.04)$, competence NS $(\beta=$

$18.09, S E=.04)$, relatedness $N S(\beta=.09, S E=.04))$ but did not predict change in

19 deficiency in ability beliefs, deficiency in effort beliefs and insufficient task values ( $p>$ $20 \quad .05)$

\section{Discussion}

23 The purpose of this study was to examine whether change in the four

24 amotivation dimensions was related to change in students' perceptions of their teacher's

25 psychological need support during a six-week unit of cricket. There is evidence to 
THE EFFECT OF PERCEIVED NEED SUPPORT ON AMOTIVATION

1 indicate that amotivation in PE can lead to maladaptive behaviours such as forgetting

2 PE kit, claiming to be medically unfit and being absent from school (Ntoumanis et al;

3 2004; Shen et al; 2010a) and that need supportive environments can enhance self-

4 determination (Standage et al; 2005; Standage et al; 2006). However, limited attention

5 has been paid to exploring teacher effects on separate amotivation dimensions over

6 time.

$7 \quad$ Amotivation and need support

In the current study, perceived teacher support for all three needs negatively

9 predicted insufficient task values and unappealing task characteristics and only

10 competence need support predicted deficiency in ability beliefs at the beginning of the

11 unit of work. Therefore after the first PE lesson (Time 1), students who felt their teacher

12 had provided inadequate support for their autonomy, competence and relatedness

13 valued the cricket lesson less and may have evoked feelings of boredom and disinterest.

14 Furthermore, competence need support emerged to be the strongest predictor of

15 unappealing task characteristics as well as being the only perceived source of support

16 to negatively predict deficiency in ability beliefs. Supporting students' competence has

17 been stated in the literature as being crucial in forestalling amotivated behaviours (Deci

18 and Ryan, 2002) and aiding the internalisation process, leading to an increase in

19 intrinsic motivation (Ryan and Deci, 2000). Given that teachers are the primary agents

20 to support ability among students and enhance their self-regulation, training needs to be

21 put in place to provide teachers with knowledge as to how to deliver instructions,

22 provide feedback and subsequently foster the student-teacher relationship.

23 The findings at Time 1 were partially supported by research from Shen and

24 colleagues (2010b) who also revealed that perceived teachers' competence and

25 relatedness support negatively correlated with unappealing task characteristics. 
THE EFFECT OF PERCEIVED NEED SUPPORT ON AMOTIVATION

1 Additionally, Vlachopoulos et al, (2013) examined the validity of the AI-PE by

2 exploring the associations of the amotivation variables with self-determination variables

3 such as needs for autonomy, competence and relatedness. These authors found that

4 competence need support negatively predicted deficient ability beliefs but together with

5 relatedness need support, did not predict unappealing task characteristics or

6 insufficient task values. Inconsistent findings across studies reinforce that researchers

7 need to further explore relationships between low perceived need support and

8 amotivation.

9 The findings at Time 1 did not correspond exactly with the results that emerged

10 over time. Perceived teacher need support in all three needs negatively predicted change

11 in students' unappealing task characteristics over the unit of work but did not predict

12 change in other amotivation dimensions. The results indicate that a six-week unit of

13 work may have been too short to see significant changes between the beginning and end

14 of the study. Nevertheless, if a student feels the teacher is not supporting their need to

15 have control over the decisions they make (low autonomy), not enabling them to

16 confidently interact in the PE setting (low competence), and perhaps unintentionally

17 creating environments whereby they do not feel accepted by their peers (low

18 relatedness), then students are more likely to find the task boring and lose interest. The

19 practical implications for the teacher as a result of these findings are that students may

20 become disengaged from the lesson and may be 'turned off' cricket in the future. An

21 important pedagogical understanding for PE teachers is that one student may be

22 amotivated in one activity due to lack of interest (Hidi and Harackiewicz, 2000) but

23 have self-determined motivation in another due to its appeal. The PE curriculum offers

24 diverse physical activities to cater for students' personal interests and, therefore, it can

25 be a challenging environment for teachers to foster high quality motivation in all 
THE EFFECT OF PERCEIVED NEED SUPPORT ON AMOTIVATION

1 students (Sun and Cheng, 2008). Not all activities are intrinsically interesting for

2 everyone. Some students, for example, may not enjoy running, but because it is a

3 worthwhile activity for improving cardiovascular fitness, teachers need to help motivate

4 students by educating them on the importance and value of the task. Future research

5 would do well to explore changes in amotivation dimensions across different activities

6 to help teachers provide additional need support in activities that are less appealing and

7 less valued among students.

8 Disconfirming our hypothesis, changes in perceptions of autonomy, competence

9 and relatedness support did not significantly predict changes in deficiency in ability

10 beliefs, deficiency in effort beliefs or insufficient task values. In other words, even if a

11 student perceived their teacher to support their needs, no significant change would

12 occur in the aforementioned amotivation subtypes. Again, an explanation may lie in the

13 six-week unit of work being too short, therefore not allowing enough time for change to

14 occur. It may take time for some students to develop relationships with their teacher and

15 subsequently students may have found it difficult to report accurate perceptions of

16 teacher need support in a limited time frame. Moreover, it may take longer to observe

17 change in a students' deficiency in ability and effort beliefs as these amotivation

18 dimensions are focused on students' feelings towards themselves. Such personal

19 preconceptions may be more difficult than task-related perceptions for students to

20 modify without enduring support and attention from the teacher. Positive feedback to

21 enhance feelings of competence and encouragement from the teacher are a necessity.

22 The teacher is required to know and understand their students' individual needs in order 23 to improve their learning in PE.

\section{$24 \quad$ Limitations and future research}




\section{THE EFFECT OF PERCEIVED NEED SUPPORT ON AMOTIVATION}

There are several limitations to be considered in evaluating the current findings.

2 First, no causal inferences could be made in relation to the associations between

3 perceived need support and amotivation. However, the findings are supported by

4 previous empirical evidence to suggest the importance of need support for change in

5 amotivated behaviours (Shen et al; 2010b; Vlachopolous et al; 2013). Second, this study

6 did not measure students' need satisfaction plus other variables that might have had an

7 influence on amotivation, e.g. past experiences. According to SDT, social-contextual

8 factors such as perceptions of need support should have an indirect influence on

9 motivational regulations via the satisfaction of the three basic psychological needs (Cox

10 and Williams, 2008; Deci and Ryan, 2000; Vallerand, 2001). Future studies should,

11 therefore, recognise need satisfaction as an important mediator between the

12 environment and the amotivation subtypes.

13 Moreover, recent research has begun to explore Deci and Ryan's (2000)

14 contention that psychological need thwarting will lead to ill-being and maladaptive

15 outcomes. Not all previous literature has found low need support and low need

16 satisfaction to relate to maladaptive outcomes, perhaps due to not explicitly assessing

17 the 'darker side of teaching' (Bartholomew et al; 2011). Thus, perceptions of teacher

18 need thwarting may be a stronger indicator of amotivated behaviours among students.

19 Future research should investigate students' perceptions of need thwarting by the

20 teacher, inadequate need support, and their subsequent effects on the four amotivation

21 dimensions.

22 The present findings were also based on a relatively small adolescent male

23 sample, so are unable to be generalised to female adolescents. Evidence suggests that

24 female adolescents are more likely to be amotivated than boys (Sallis et al; 2000; Wang

25 et al; 2002) and, therefore, studies exploring the gender differences in amotivation in a 
THE EFFECT OF PERCEIVED NEED SUPPORT ON AMOTIVATION

1 PE context would be welcomed and beneficial for physical educators. Furthermore, due

2 to the present study being longitudinal, attrition was evident. The sample size decreased

3 from 162 participants at the start of the study to 130 participants at the end. This decline

4 can be explained by students being absent from school or the PE lesson, non-

5 participation due to illness or injury, or not completing the questionnaire sufficiently to

6 obtain recordable responses. It could be argued that these specific students might

7 display amotivated behaviours towards $\mathrm{PE}$ and as a consequence, the present study may

8 include a biased sample. Overcoming this predicament is challenging for researchers, as

9 highly amotivated students are likely to be those individuals who do not participate in

10 the PE lesson. However, although students' mean amotivation scores were low,

11 (suggesting self-determined motivation was present), this study identifies teachers as

12 being a potential influence on changing students' levels of amotivation scores over

13 time. Teacher behaviours that have been identified in the literature to support the three

14 basic needs are structure, interpersonal involvement and autonomy support. Findings

15 have suggested that teacher training in how to effectively provide these three behaviours

16 in lessons has resulted in a decrease in student amotivation (Tessier et al; 2010). Further

17 research is needed to be able to guide teachers on how to successfully support students'

18 psychological needs. Likewise, more longitudinal studies are needed to observe change

19 in amotivation over a longer period of time in the PE context controlling for

20 confounding variables. Although PSC was not found to be a significant predictor of

21 amotivation in the current study, future research nevertheless should identify key

22 moderating influences.

23 In conclusion, current findings highlight the importance of teachers to create an

24 environment that supports the basic psychological needs and forestalls the development

25 of amotivation among some students. As indicated by the results, teachers who 


\section{THE EFFECT OF PERCEIVED NEED SUPPORT ON AMOTIVATION}

1 inadequately support students' autonomy, competence and relatedness in PE may evoke

2 feelings of boredom, and disinterest in the PE lesson. Over time, students subsequently

3 may display avoidance behaviours such as opting for more sedentary roles in the lesson,

4 purposely forgetting their PE kit, and poor attendance (Ntoumanis et al; 2004). It is

5 imperative, therefore, that teachers are encouraged to seek and employ strategies to

6 modify their behaviours and create need supportive environments. Future studies would

7 do well to examine predictors of change in amotivation over a longer time period and

8 across a number of different activities involving boys and girls. Larger scale

9 investigations could also yield data revealing the class-level, as well as individual-level

10 influences on amotivation among adolescents. As a result a more comprehensive

11 understanding of motivational processes in PE will be achieved.

\section{References}

14 Ainley M, Hidi S and Berndoff D (2002) Interest, learning, and the psychological processes that mediate their relationship. Journal of Educational Psychology 94(3): 545-561.

\section{Alderman BL, Beighle A and Pangrazi RP (2006) Enhancing motivation in physical} education. Journal of Physical Education, Recreation and Dance 77(2): 41-51.

Bartholomew JK, Ntoumanis N, Ryan MR and Thogerson-Ntoumani C (2011)

Psychological need thwarting in the sport context: assessing the darker side of athletic experience. Journal of Sport and Exercise Psychology 33(1): 75-102.

Bentler PM (2003) EQS 6.1 for Windows [Computer software]. Encino, CA: Multivariate 7 Software.

24 Biddle SJH, Sallis JF and Cavill N (eds) (1998) Young and Active? Young people and 
THE EFFECT OF PERCEIVED NEED SUPPORT ON AMOTIVATION

Health-Enhancing Physical Activity: Evidence and Implications. London: Health Education Authority.

3 Cox EA and Williams L (2008) The roles of perceived teacher support, motivational

4 climate, and psychological need satisfaction in students' physical education motivation. Journal of Sport and Exercise Psychology 30: 222-239.

6 Deci EL and Ryan RM (1985) Intrinsic motivation and self-determination in human behaviour. New York: Plenum.

8 Deci EL and Ryan RM (1991) A motivational approach to self: Integration in personality. In: Dienstbier R (ed) Nebraska symposium on motivation: Vol. 38

12 Deci EL, Eghrari H, Patrick BC and Leone D (1994) Facilitating internalization: The self- determination theory perspective. Journal of Personality 62(1): 119-142.

14 Deci EL and Ryan RM (2000) The "what" and "why" of goal pursuits: Human needs and the self-determination of behaviour. Psychological Inquiry 11(4): 227-268.

Deci EL and Ryan RM (2008) Facilitating optimal motivation and psychological wellbeing across life's domains. Canadian Psychology 49(1): 14-23.

21 Eccles JS, Wigfield A, Midgley C, Reuman, D, Maelver D and Feldlaufer H (1993) Negative effects of traditional middle schools on students' motivation. Elementary School Journal 93(5): 553 - 574.

24 Green-Demers I, Legault L, Pelletier D and Pelletier LG (2008) Factorial invariance of 
THE EFFECT OF PERCEIVED NEED SUPPORT ON AMOTIVATION

1 the academic amotivation inventory across gender and grade in a sample of Canadian high school students. Educational and Psychological Measurement 68(5): 862-880.

Gutin B, Barbeau P and Yin Z (2004) Exercise interventions for prevention of obesity and related disorders in youth. Quest 56(1): 120-141.

Hidi S and Harackiewicz JM (2000) Motivating the academically unmotivated: A critical issue for the $21^{\text {st }}$ century. Review of Educational Research 70(2): 151179.

Health Survey for England (HSE) (2012) Physical activity in children. Available at www.hscic.gov.uk/catalogue/PUB13218/HSE2012-Ch3-Phys-act-child.pdf (accessed 21 February 2015).

Hox J (2002) Multilevel analysis: Techniques and applications. Mahwah NJ: Laurence Erlbaum.

Jackson-Kersey RM and Spray CM (2013) Amotivation in physical education: relationships with physical self-concept and teacher ratings of attainment. European Physical Education Review 19(3): 289-301.

Koka A and Hagger SM (2010) Perceived teaching behaviours and self-determined motivation in physical education: a test of self-determination theory. Research Quarterly for Exercise and Sport 81(1): 74-86.

Legault L, Green-Demers I and Pelletier L (2006) Why do high school students lack motivation in the classroom? Toward an understanding of academic motivation and the role of social support. Journal of Educational Psychology 98(3): 567582. 


\section{THE EFFECT OF PERCEIVED NEED SUPPORT ON AMOTIVATION}

1 Malina MR and Katzmarzyk TP (2006) Physical activity and fitness in an international growth standard for preadolescent and adolescent children. Food and Nutrition Bulletin 27(4): 295-213. 34.

Ntoumanis N (2001) A self-determination approach to the understanding of motivation in physical education. British Journal of Educational Psychology 71: 225-242.

Ntoumanis N, Pensgaard MA, Martin C and Pipe K (2004) An idiographic analysis of amotivation in compulsory school physical education. Journal of Sport and Exercise Psychology 26: 197-214.

Perlman D (2010) Change in affect and needs satisfaction for amotivated students within the sport education model. Journal of Teaching in Physical Education 29: $24 \quad$ Information Age Press, 31-60. 


\section{THE EFFECT OF PERCEIVED NEED SUPPORT ON AMOTIVATION}

1 Reeve J and Jang H (2006) What teachers say and do to support students' autonomy during learning activity. Journal of Educational Psychology 98(1): 209-218.

3 Ryan RM and Deci EL (2000) Self-determination theory and the facilitation of intrinsic motivation, social development, and well-being. American Psychologist 55(1): $66-78$.

6 Ryan RM and Deci EL (2009) Promoting self-determined school engagement: motivation, learning, and well-being. In KR Wentzel and A Wigfield (Eds.) Handbook of motivation at school. New York: Routledge.

Sallis J and McKenzie TL (1991) Physical education's role in public health. Research Quarterly for Exercise and Sport 62(2): 124-137.

Sallis JF, Prochaska JJ and Taylor WC (2000) A review of correlates of physical activity of children and adolescents. Medicine and Science in Sports and Exercise 32(5): 963-975.

Shen B, Wingert KR, Weidong L, Sun H and Rukavina BP (2010a) An amotivation model in physical education. Journal of Teaching in Physical Education 29: 7284.

Shen B, Weidong L, Sun H and Rukavina BP (2010b) The influence of inadequate teacher-to-student social support on amotivation of physical education students. Journal of Teaching in Physical Education 29: 417-432.

Singer DJ and Willett BJ (2003) Applied Longitudinal Data Analysis: Modelling Change and Event Occurrence. New York: Oxford University Press.

Skinner E and Edge K (2002) Self-determination, coping, and development. In: Deci EL and Ryan RM (eds) Handbook of self-determination research. Rochester, NY: University of Rochester Press, pp. 297-337. 
THE EFFECT OF PERCEIVED NEED SUPPORT ON AMOTIVATION

1 Standage M, Duda J and Ntoumanis N (2005) A test of self-determination theory in school physical education. British Journal of Educational Psychology 75: 411433.

4 Standage M, Duda J and Ntoumanis N (2006) Students' motivational processes and their relationship to teacher ratings in school physical education: A self-

Sun $\mathrm{H}$ and Cheng A (2008) A pedagogical understanding of the self-determination theory in physical education. Quest 62(4): 364-384.

Tessier D, Sarrazin P and Ntoumanis N (2010) The effect of an intervention to improve newly qualified teachers' interpersonal style, students' motivation and psychological need satisfaction in sport-based physical education.

Contemporary Educational Psychology 35: 242-253.

Vallerand RJ (2001) A hierarchical model of intrinsic and extrinsic motivation in sport and exercise. In: Roberts GC (ed). Advances in motivation in sport and exercise Champaign: Human Kinetics, pp. 263-320.

Vlachopoulos SP, Katartzi ES and Kontou GM (2013) Fitting multidimensional amotivation into the self-determination theory nomological network: application in school physical education. Measurement in Physical Education and Exercise Science 17(1): 40-61.

Ward J, Wilkinson C, Vincent-Graser S and Prusak K (2008) Effects of choice on student motivation and physical activity behaviour in physical education. Journal of Teaching in Physical Education 27: 385-398.

24 Wang CKJ, Chatzisarantis NLD, Spray CM and Biddle SJH (2002) Achievement 
THE EFFECT OF PERCEIVED NEED SUPPORT ON AMOTIVATION goal profiles in school physical education: differences in self-determination, sport ability beliefs, and physical activity. British Journal of Educational Psychology 72(3): 433-445.

4 Wigfield A and Eccles JS (2000) Expectancy-Value theory of achievement motivation. 
THE EFFECT OF PERCEIVED NEED SUPPORT ON AMOTIVATION

Table 1. Means, Standard Deviations, and Reliability Coefficients for all Variables Across the Three Time Points

\begin{tabular}{|c|c|c|c|c|c|c|c|c|c|}
\hline \multirow[b]{2}{*}{ Variable } & \multicolumn{3}{|c|}{$\begin{array}{c}\text { Time } 1 \\
(\mathrm{n}=162)\end{array}$} & \multicolumn{3}{|c|}{$\begin{array}{c}\text { Time } 2 \\
(\mathrm{n}=141)\end{array}$} & \multicolumn{3}{|c|}{$\begin{array}{c}\text { Time } 3 \\
(\mathrm{n}=130)\end{array}$} \\
\hline & $M$ & $S D$ & $\alpha$ & $M$ & $S D$ & $\alpha$ & $M$ & $S D$ & $\alpha$ \\
\hline Deficiency in $\mathrm{AB}$ & 2.16 & 1.25 & 0.85 & 2.21 & 1.30 & 0.82 & 2.26 & 1.31 & 0.91 \\
\hline Deficiency in EB & 2.27 & 1.44 & 0.92 & 2.33 & 1.47 & 0.92 & 2.26 & 1.29 & 0.90 \\
\hline Insufficient TV & 2.30 & 1.61 & 0.91 & 2.33 & 1.71 & 0.96 & 2.45 & 1.58 & 0.94 \\
\hline Unappealing TC & 2.46 & 1.45 & 0.85 & 2.59 & 1.62 & 0.92 & 2.59 & 1.60 & 0.93 \\
\hline Autonomy NS & 3.61 & 1.60 & 0.85 & 3.73 & 1.87 & 0.91 & 3.96 & 1.80 & 0.90 \\
\hline Competence NS & 4.86 & 1.55 & 0.85 & 4.36 & 1.78 & 0.89 & 4.32 & 1.80 & 0.92 \\
\hline Relatedness NS & 4.85 & 1.48 & 0.86 & 4.37 & 1.76 & 0.90 & 4.29 & 1.82 & 0.94 \\
\hline PSC & 4.51 & 1.25 & 0.96 & 4.54 & 1.34 & 0.96 & 4.50 & 1.39 & 0.97 \\
\hline
\end{tabular}

Note: $\mathrm{AB}=$ Ability beliefs; $\mathrm{EB}=$ Effort beliefs; $\mathrm{TV}=$ Task Value; $\mathrm{TC}=$ Task Characteristics; $\mathrm{PSC}=$ Physical Self-Concept NS $=$ Need Support 
THE EFFECT OF PERCEIVED NEED SUPPORT ON AMOTIVATION

Table 2. Correlations Among the Amotivation Dimensions, Perceptions of Teacher Psychological Need Support and Physical Self-Concept at Time 1

\begin{tabular}{|c|c|c|c|c|c|c|c|c|}
\hline Variable & 1 & 2 & 3 & 4 & 5 & 6 & 7 & 8 \\
\hline 1. Deficiency in $A B$ & - & & & & & & & \\
\hline 2. Deficiency in EB & $.64 * *$ & - & & & & & & \\
\hline 3. Insufficient TV & $.75^{* *}$ & $.59 * *$ & - & & & & & \\
\hline 4. Unappealing TC & $.67 * *$ & $.56^{* *}$ & $.79 * *$ & - & & & & \\
\hline 5. Autonomy NS & $-.26 * *$ & -.14 & $-.31 * *$ & $-.40 * *$ & - & & & \\
\hline 6. Competence NS & $-.29 * *$ & -.14 & $-.37 * *$ & $-.43 * *$ & $.79 * *$ & - & & \\
\hline 7. Relatedness NS & $-.24 * *$ & -.11 & $-.31 * *$ & $-.36^{* *}$ & $.81 * *$ & $.92 * *$ & - & \\
\hline 8. PSC & $-.44 * *$ & $-.31 * *$ & $-.16^{* *}$ & $-.22 * *$ & $.25 * *$ & $.23 * *$ & $.22 * *$ & \\
\hline
\end{tabular}

Note: $\mathrm{AB}=$ Ability beliefs; $\mathrm{EB}=$ Effort beliefs; $\mathrm{TV}=$ Task Value; $\mathrm{TC}=$ Task Characteristics; $\mathrm{PSC}=$ Physical Self-Concept; NS = Need Support $* * p<.01$ 
THE EFFECT OF PERCEIVED NEED SUPPORT ON AMOTIVATION

Table 3. Final Models of Students' Perceptions of Teacher Psychological Need Support Predicting Amotivation Dimensions

\begin{tabular}{|c|c|c|c|c|c|c|c|c|}
\hline \multirow[t]{2}{*}{ Predictors } & \multicolumn{2}{|c|}{ Deficiency in $\mathrm{AB}$} & \multicolumn{2}{|c|}{ Deficiency in EB } & \multicolumn{2}{|c|}{ Insufficient TV } & \multicolumn{2}{|c|}{ Unappealing TC } \\
\hline & $\beta$ & SE & $\beta$ & SE & $\beta$ & SE & $\beta$ & SE \\
\hline \multicolumn{9}{|l|}{ Initial status } \\
\hline Intercept & 2.17 & $(.09)^{*}$ & 2.30 & $(.11)^{*}$ & 2.31 & $(.12)^{*}$ & 2.50 & $(.12)^{*}$ \\
\hline Autonomy NS & -.06 & $(.05)$ & -.04 & $(.06)$ & -.15 & $(.06)^{*}$ & -.17 & $(.06)^{*}$ \\
\hline Competence NS & -.10 & $(.05)^{*}$ & -.05 & $(.05)$ & -.17 & $(.06)^{*}$ & -.19 & $(.05)^{*}$ \\
\hline Relatedness NS & -.08 & $(.05)$ & -.05 & $(.06)$ & -.15 & $(.06)^{*}$ & -.16 & $(.06)^{*}$ \\
\hline \multicolumn{9}{|l|}{ Rate of change } \\
\hline Intercept & .04 & $(.05)$ & -.01 & $(.06)$ & .05 & $(.06)$ & .05 & $(.06)$ \\
\hline Autonomy NS & -.02 & $(.03)$ & -.06 & $(.04)$ & -.04 & $(.04)$ & -.08 & $(.04)^{*}$ \\
\hline Competence NS & -.01 & $(.03)$ & -.06 & $(.04)$ & -.04 & $(.04)$ & -.09 & $(.04)^{*}$ \\
\hline Relatedness NS & -.02 & $(.03)$ & -.04 & $(.04)$ & -.04 & $(.04)$ & -.09 & $(.04)^{*}$ \\
\hline \multicolumn{9}{|l|}{ Variance } \\
\hline Student $(u)$ & .96 & $(.14)^{*}$ & 1.05 & $(.16)^{*}$ & 1.73 & $(.23)^{*}$ & 1.52 & $(.21)^{*}$ \\
\hline Residual (e) & .65 & $(.06)^{*}$ & .92 & $(.08)^{*}$ & .91 & $(.08)^{*}$ & .90 & $(.08)^{*}$ \\
\hline
\end{tabular}

Note: $\mathrm{AB}=$ Ability beliefs; $\mathrm{EB}=$ Effort beliefs; $\mathrm{TV}=$ Task Value; $\mathrm{TC}=$ Task Characteristics; $\mathrm{NS}=$ Need Support $\beta=$ Beta; $\mathrm{SE}=$ Standard Error ${ }^{*} p<.01$ 